\title{
Evaluating the Impact of National Public Health Department Accreditation - United States, 2016
}

\author{
Jessica Kronstadt, MPP ${ }^{1}$; Michael Meit, $\mathrm{MPH}^{2}$; Alexa Siegfried, $\mathrm{MPH}^{2}$; Teddi Nicolaus ${ }^{1}$; Kaye Bender, $\mathrm{PhD}^{1}$; Liza Corso, $\mathrm{MPA}^{3}$
}

In 2011, the nonprofit Public Health Accreditation Board (PHAB) launched the national, voluntary public health accreditation program for state, tribal, local, and territorial public health departments. As of May 2016, 134 health departments have achieved 5-year accreditation through $\mathrm{PHAB}$ and 176 more have begun the formal process of pursuing accreditation. In addition, Florida, a centralized state in which the employees of all 67 local health departments are employees of the state, achieved accreditation for the entire integrated local public health department system in the state. PHAB-accredited health departments range in size from a small Indiana health department that serves approximately 17,000 persons to the much larger California Department of Public Health, which serves approximately 38 million persons. Collectively, approximately half the U.S. population, or nearly 167 million persons, is covered by an accredited health department. Forty-two states and the District of Columbia now have at least one nationally accredited health department. In a survey conducted through a contract with a social science research organization during 2013-2016, $>90 \%$ of health departments that had been accredited for 1 year reported that accreditation has stimulated quality improvement and performance improvement opportunities, increased accountability and transparency, and improved management processes.

In 2003, the Institute of Medicine published a report on the future of the public's health in the 21 st century. The report discussed the need to strengthen public health infrastructure, and recommended accreditation as a potential strategy (1). With support from CDC and the Robert Wood Johnson Foundation, and participation by hundreds of public health practitioners and other technical experts, the first national accreditation program for health departments was developed (2). PHAB was incorporated in 2007. Its mission is to improve and protect the health of the public by advancing and transforming the quality and performance of governmental public health departments, ${ }^{*}$ of which there are approximately 2,500 in the United States. Drawing on existing public health standards, and using a consensus process (3), PHAB developed and tested a set of standards and measures organized

*http://www.phaboard.org. around the 10 Essential Public Health Services. ${ }^{\dagger}$ Health departments are encouraged to assess themselves against the standards and measures to identify and fill gaps before applying. The amount of time health departments spend in preparation for accreditation will vary based on their readiness. Once they determine they are ready, they submit an application, pay a fee based on the size of the population of the jurisdiction they serve, and provide documentation for each measure, including a community health assessment, a community health improvement plan, and an organizational strategic plan. Volunteer peer site visitors review the documentation and assess its conformity with the measures. The PHAB Accreditation Committee reviews the site visit report and determines whether the applicant will be accredited at that time or be required to develop and implement an action plan (4). Using this process, health departments in 45 states and the District of Columbia have applied for accreditation. (Figure). Working with CDC and other national partners, $\mathrm{PHAB}$ is widely disseminating the benefits of accreditation to health departments and the communities they serve, and working to raise awareness about technical assistance and other resources to support the pursuit of accreditation.

To identify opportunities to improve the accreditation process and to understand the impact of accreditation, in 2013, PHAB contracted with a social science research organization, NORC at the University of Chicago, ${ }^{\S}$ to conduct an evaluation. Among other data collection and analysis strategies, NORC surveys health departments 1 year after they have been accredited. Most survey questions ask respondents to indicate whether they "strongly agree," "agree," "disagree," or "strongly disagree" with (or "don't know" about) a series of

\footnotetext{
†The 10 Essential Public Health Services are to 1) monitor health status to identify and solve community health problems; 2) diagnose and investigate health problems and health hazards in the community; 3) inform, educate, and empower persons about health issues; 4) mobilize community partnerships to identify and solve health problems; 5) develop policies and plans that support individual and community health efforts; 6) enforce laws and regulations that protect health and ensure safety; 7) link persons to needed personal health services and assure the provision of health care when otherwise unavailable; 8) assure competent public and personal health care workforce; 9) evaluate effectiveness, accessibility, and quality of personal and population-based health services; and 10) research for new insights and innovative solutions to health problems. http://www.cdc.gov/nphpsp/essentialservices.html. $\$$ http://www.norc.org.
} 
FIGURE. Number ${ }^{*},+$ of Public Health Accreditation Board-accredited health departments (HDs) — United States, May 2016

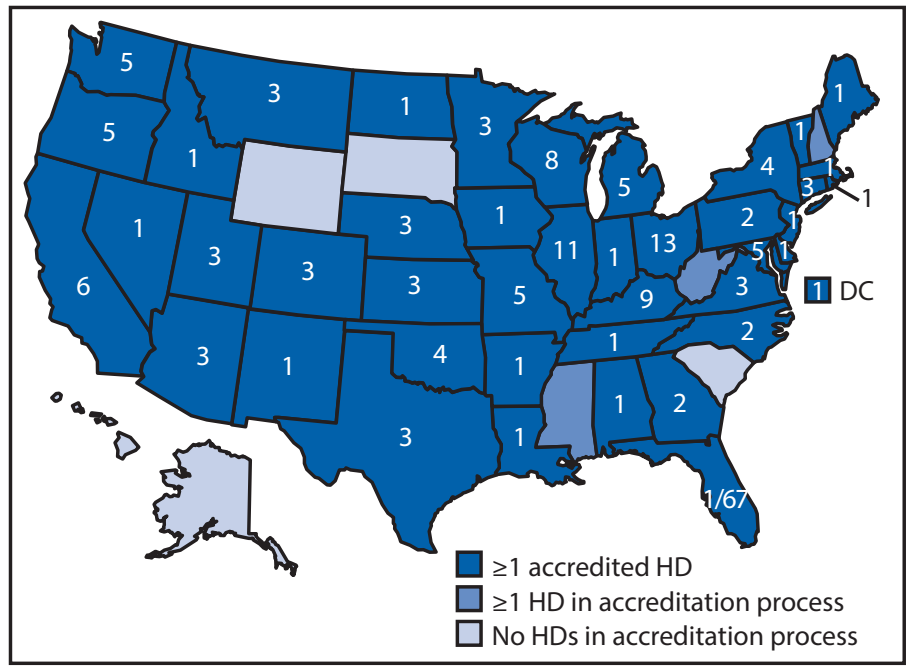

* Number indicates the total number of accredited HDs in that state.

$\dagger$ Accreditation of Florida's local public health department system, made up of $67 \mathrm{HDs}$.

accreditation-related statements. Data in this report were obtained from surveys sent to health departments quarterly throughout October 2013-January 2016. During this time, the survey was sent to 60 health departments, $52(87 \%)$ of which responded. In addition to this survey, NORC conducted three focus groups and 18 interviews with health department personnel and stakeholders to gain additional insights about health departments' experiences with accreditation and its perceived impact.

The overwhelming majority of survey respondents agreed or strongly agreed that accreditation stimulated quality and performance improvement opportunities within the health department (98\%), allowed the health department to better identify strengths and weaknesses (96\%), helped the health department document capacity to deliver the three core functions of public health (i.e., assessment, policy development, and assurance) and the 10 Essential Public Health Services (94\%), stimulated greater accountability and transparency within the health department (92\%), and improved the management processes used by the leadership team in the health department (90\%) (Table). Most respondents also agreed or strongly agreed that accreditation improved the health department's accountability to external stakeholders (83\%) and allowed the health department to communicate better with the board of health or governing entity (67\%). Other accreditation benefits reported by accredited health departments that participated in focus groups and interviews include improved visibility, credibility, and reputation among their community partners, board of health, and public health peers within the state and nationally; improved identification and use of evidence-based programs and metrics; and increased cross-department collaboration.

Because quality improvement is an important focus of the accreditation process, the evaluation gathered additional information about health departments' engagement in quality improvement. Among health departments that had been accredited for 1 year, $98 \%$ of survey respondents agreed or strongly agreed that, as a consequence of the accreditation process, the health department had used information from quality improvement processes to inform decisions. In addition, $92 \%$ of survey respondents agreed or strongly agreed that because of accreditation, the health department had a strong quality improvement culture (Table). In a focus group discussion with 12 accredited local health departments, participants described how accreditation provided an opportunity for their health department to evolve from one that only periodically used quality improvement to an organization that viewed improvement and data-driven performance management as part of standard operations.

TABLE. Impacts of public health accreditation and the accreditation process reported by health departments accredited by the Public Health Accreditation Board for 1 year $(n=52), 2014-2016$

\begin{tabular}{|c|c|c|c|c|c|}
\hline Impact of accreditation & $\begin{array}{l}\text { Strongly agree } \\
(\%)\end{array}$ & $\begin{array}{l}\text { Agree } \\
(\%)\end{array}$ & $\begin{array}{l}\text { Disagree } \\
(\%)\end{array}$ & $\begin{array}{c}\text { Strongly } \\
\text { disagree (\%) }\end{array}$ & $\begin{array}{l}\text { Don't know } \\
(\%)\end{array}$ \\
\hline $\begin{array}{l}\text { Stimulated quality and performance improvement opportunities within the } \\
\text { health department }\end{array}$ & $31(60)$ & $20(38)$ & $1(2)$ & $0(0)$ & $0(0)$ \\
\hline Allowed the health department to better identify strengths and weaknesses & $33(63)$ & $17(33)$ & $2(4)$ & $0(0)$ & $0(0)$ \\
\hline $\begin{array}{l}\text { Helped the health department document the capacity to deliver the three core } \\
\text { functions of public health and Ten Essential Public Health Services }\end{array}$ & $25(48)$ & $24(46)$ & $2(4)$ & $0(0)$ & $1(2)$ \\
\hline Stimulated greater accountability and transparency within the health department & $22(42)$ & $26(50)$ & $3(6)$ & $0(0)$ & $1(2)$ \\
\hline $\begin{array}{l}\text { Improved the management processes used by the leadership team in the } \\
\text { health department }\end{array}$ & $16(32)$ & $29(58)$ & $3(6)$ & $0(0)$ & $2(4)$ \\
\hline Improved the health department's accountability to external stakeholders & $17(33)$ & $26(50)$ & $7(13)$ & $0(0)$ & $2(4)$ \\
\hline $\begin{array}{l}\text { Allowed the health department to better communicate with the board of health or } \\
\text { governing entity }\end{array}$ & 10 (19) & $25(48)$ & $12(23)$ & $1(2)$ & $4(8)$ \\
\hline Improved the health department's competitiveness for funding opportunities & $11(21)$ & $15(29)$ & $13(25)$ & $3(6)$ & $10(19)$ \\
\hline \multicolumn{6}{|l|}{ Quality improvement } \\
\hline $\begin{array}{l}\text { Health department has used information from the quality improvement processes } \\
\text { to inform decisions }\end{array}$ & $27(53)$ & $23(45)$ & $1(2)$ & $0(0)$ & $0(0)$ \\
\hline Health department has a strong culture of quality improvement & $17(33)$ & $30(59)$ & $3(6)$ & $0(0)$ & $1(2)$ \\
\hline
\end{tabular}




\section{Summary}

What is already known about this topic?

In 2011, the Public Health Accreditation Board launched the national, voluntary public health accreditation program as a strategy to advance the quality and performance of governmental public health departments. As of May 2016, 134 state and local health departments have been accredited. In addition, Florida, in which employees of all 67 local health departments are employees of the state, achieved accreditation for the entire integrated local public health department system in the state. Collectively, nearly 167 million persons, approximately half the U.S. population, are covered by an accredited health department.

What is added by this report?

A survey of health departments that had been accredited for one year indicates that $>90 \%$ report experiencing benefits such as stimulation of quality improvement and performance improvement opportunities; increased accountability and transparency; and improved management processes.

What are the implications for public health practice?

As governmental public health departments work to promote and protect the public's health, it is critical that they have a strong infrastructure. Accreditation has the potential to strengthen health departments' cross-cutting capacities and infrastructure by fostering their engagement in quality improvement, strengthening management processes, and improving accountability.

\section{Discussion}

Health departments undergoing the accreditation process report multiple benefits, including increased transparency, strengthened management processes, and improved ability to identify organizational weaknesses. One of the foremost reported benefits is the increased use of quality improvement information in decision- making and in supporting a stronger culture of quality improvement. A report on a series of studies examining the response of public health decision-makers to accreditation, quality improvement, and public reporting initiatives suggests that quality improvement can strengthen implementation of evidence-based strategies and enhance the efficiency and effectiveness of public health programs (5). Health departments also report that as a result of accreditation they communicate better with their governing entities. Although this benefit is reported less frequently than some of the others, in response to an openended question, several health departments indicated that they might not have agreed that accreditation caused a specific change if the question related to an area in which they were already strong before applying.

This evaluation is the first to examine the impacts of the national public health accreditation program on quality improvement, management processes, and accountability. However, the findings are consistent with an earlier evaluation of PHAB's pilot test in 30 health departments ( 6 ) and with evaluation findings from a state-based public health accreditation program (7). Those studies found that health departments participating in accreditation activities experienced benefits related to quality improvement and collaboration. In addition, a series of case studies by applicant health departments highlights many of the same findings from the current evaluation, particularly the connection between accreditation and advancements in quality improvement (8).

The findings in this report are subject to at least three limitations. First, all survey data are self-reported and have not been verified independently. Social desirability bias could result in respondents overreporting their quality improvement activities. Second, survey respondents are among the early adopters of accreditation. Although the health departments included in this study were diverse in size, geographic location, and structure, they might not be representative of all health departments. Finally, because accreditation is a voluntary program, selection bias might apply. For example, health departments are required to provide examples of quality improvement activities to demonstrate conformity with the PHAB standards. Therefore, health departments that were already active in this area might be more likely to apply, particularly in the first few years of the accreditation program. As a growing number of health departments are accredited, future studies can use other quantitative techniques to study the effects of accreditation.

The 2003 Institute of Medicine report that recommended that the public health field explore accreditation also described the need for governmental public health agencies to have strong organizational capabilities. Strengthening health departments' cross-cutting capacities and infrastructure (9) might allow health departments to partner more effectively with community organizations, health care organizations, and other stakeholders to improve the public's health. The initial evaluation findings reported in this study suggest that health departments that have participated in the accreditation process have experienced these intended benefits.

\footnotetext{
${ }^{1}$ Public Health Accreditation Board, Alexandria, Virginia; ${ }^{2}$ NORC at the University of Chicago, Bethesda, Maryland; ${ }^{3}$ Division of Public Health Performance Improvement, Office for State, Tribal, Local and Territorial Support, CDC.

Corresponding author: Jessica Kronstadt, jkronstadt@phaboard.org, 703-778-4549.
}

\section{References}

1. Institute of Medicine. The future of the public's health in the 21 st century. Washington, DC: National Academies Press; 2003.

2. Bender K, Benjamin G, Carden J, et al. Final recommendations for a voluntary national accreditation program for state and local health departments: steering committee report. J Public Health Manag Pract 2007;13:342-8. http://dx.doi.org/10.1097/01. PHH.0000278026.49196.40 
3. Ingram RC, Bender K, Wilcox R, Kronstadt J. A consensus-based approach to national public health accreditation. J Public Health Manag Pract 2014;20:9-13. http://dx.doi.org/10.1097/PHH.0b013e3182a0b8f9

4. Bender K, Kronstadt J, Wilcox R, Lee TP. Overview of the public health accreditation board. J Public Health Manag Pract 2014;20:4-6. http:// dx.doi.org/10.1097/PHH.0b013e3182a778a0

5. Mays GP. Stimulating public health improvement in complex and constrained delivery systems: findings from the public health PBRNs. Front Public Health Serv Syst Res 2012;1-7.

6. NORC at the University of Chicago. Brief report: evaluation of the Public Health Accreditation Board beta test. Chicago, IL: NORC at the University of Chicago; 2011. http://www.phaboard.org/wp-content/ uploads/EvaluationofthePHABBetaTestBriefReportAugust2011.pdf
7. Davis MV, Cannon MM, Stone DO, Wood BW, Reed J, Baker EL. Informing the national public health accreditation movement: lessons from North Carolina's accredited local health departments. Am J Public Health 2011;101:1543-8. http://dx.doi.org/10.2105/AJPH.2011.300199

8. Joly B, Davis MV. Introduction to case reports: one goal-many journeys. J Public Health Manag Pract 2014;20:64-5. http://dx.doi.org/10.1097/ PHH.0b013e3182a958da

9. US Department of Health and Human Services. Healthy People 2020. Public health infrastructure. Washington, DC: US Department of Health and Human Services, Office of Disease Prevention and Health Promotion; 2016. https://www.healthypeople.gov/2020/topics-objectives/topic/ public-health-infrastructure 